\title{
ASSESSMENT OF KNOWLEDGE IN SAMPLE OF IRAQI PATIENTS WITH ANKYLOSING SPONDYLITIS
}

\author{
N. A. Jassim¹, S. H. Majeed² \\ ${ }^{1}$ Rheumatologist, College of Medicine, University of Baghdad - Baghdad, Iraq \\ ${ }^{2}$ Rheumatology Department, Al-Kindy Teaching Hospital, Ministry of Health/Environment - Baghdad, Iraq
}

\begin{abstract}
The aim of the present study is to assess a level of knowledge in a sample of Iraqi patients with ankylosing spondylitis (AS) by a self-administered questionnaire. This is a cross-sectional study, including 200 Iraqi patients with AS, who have access to the Rheumatology Unit, Baghdad Teaching Hospital. AS Data collection was taking place between November 2017 and September 2018. Socio-demographic data were reported, including age, residence, marital status, smoking, educational level, occupation, and disease diagnosis duration. Patients had undergone an interview with a physician to assess their level of knowledge by a questionnaire, which included 4 knowledge areas: Area A includes general knowledge about AS, comprising etiology, symptoms musculoskeletal and extra musculoskeletal, and laboratory blood tests. Area B includes immuno-genetics test (HLA-B27 antigen) and inheritance. Area $C$ includes general management, including pharmacological treatment and its side effects, physical therapy, and exercise (exercise type \& proper duration and its role in treatment). Area $D$ includes joints protection, pacing, and priorities. The clinical and demographic data were analyzed using descriptive statistics. The mean total questionnaire score is $16.28 \pm 2.49$, range $(2-26)$. There is no significant statistical association between the mean total score and the gender $(p=0.14)$, age $(p=0.93)$, marital status $(p=0.73)$, smoking $(p=$ $0.65)$, residence $(p=0.56)$, and $B M I(p=0.23)$, while there is a highly significant statistical relationship between mean total score and the level of education $(p=0.0004)$, and occupation $(p=0.0026)$. For Area $A$, the mean achieved score is $3.63 \pm 1.61$; the maximum possible score is 8 . For Area $B$, the mean achieved score is 0.26 \pm 0.51 ; the maximum possible score is 2 . For Area $C$, the mean achieved score is $9.53 \pm 2.42$; the maximum possible score is 15 . Area $D$, the mean achieved score is $2.87 \pm 1.06$; the maximum possible score is 4 . The study showed that AS Iraqi patients have a low level of knowledge, unawareness, and wrong thoughts about specific aspects of their disease, which may reinforce the recommendation of this study.
\end{abstract}

Key words: ankylosing spondylitis; Iraq; musculoskeletal symptoms; chronic inflammatory disease

\section{INTRODUCTION}

Ankylosing spondylitis (AS) is an inflammatory, rheumatic disease from the group of spondyloarthropathies (SPAs), chronic in nature, which primarily involves the sacroiliac joint and spine, less frequently peripheral joints, and can also present with extra joint involvement [1]. AS is more prevalent in males, in the ratio of 2-4:1, and most symptoms occur between 20 and 35 years of age. It takes, on average, up to 8 years from the onset of back pain until a definite diagnosis of AS [2]. A positive family history increases the probability of AS pretest from $0.1 \%$ in the general population to approximately $10 \%$ for any first degree relative of an AS [3]. AS prevalence parallels closely with the frequency of HLA-B27 [4]. This holds for those B27 subtypes that are associated with the disease, but it is not true for populations in which the HLA-B2706 subtype, which lacks a strong association with AS
$[5,6]$. HLA-B27, an allele of the major histocompatibility complex, shows a strong association with AS and related SpA [7, 8]. HLA-B27 is found in approximately $8 \%$ of the general white population (western European) and more than $90 \%$ of patients with AS. In AS Iraqi patients, the estimated prevalence was $0.9 \%$, with male to female ratio $9: 1$, and HLA-B27 was positive in 55\% [9], while $2.1 \%$ of healthy Iraqi populations were HLA-B27 positive [10]. Genetic factors such as strong association with HLA-B27 that $B^{*} 2705$ is the strongest disease-associated subtype [4, 5]. Ramos et al., 2002 reported that $B^{*} 2709$ is weakly or not associated with ankylosing spondylitis [11]. HLA-B*2705 and $B^{\star} 2709$ allotypes differ by a single $\mathrm{D} 116 \mathrm{H}$ change. They suggested that weaker association of $B^{\star} 2709$ with ankylosing spondylitis based on differential binding of a limited subset of natural ligands by this allotype $[11,12]$. Other HLA-B ${ }^{\star} 2706$ is a relatively rare subtype of HLA-B27. In contrast to most 
HLA-B27 subtypes HLA-B*2705, some studies have reported $H L A-B * 2706$ to be protective against AS [11, 12]. Regarding the immunological causes, the cytokine TNF- $\alpha$ is identified as an important mediator in the pathogenesis of AS [13]. IL-23 promotes the survival of $\mathrm{TH} 17 \mathrm{CD} 4+\mathrm{T}$ cells. TH17 cells can play a major role in inflammatory responses by various pro-inflammatory cytokines production (like IL-17, IL-6, and TNF- $\alpha$ ) and recruiting other inflammatory cells (like neutrophils) in inflammatory and infectious diseases. They may play an important role in the pathogenesis of AS and spondyloarthropathies [14]. Other causes could be environmental factors, HLA-B*2705 and nitrogenase from Klebsiella pneumoniae, which supports molecular mimicry as a possible mechanism for the induction of spondyloarthropathies in a host who is genetically susceptible via an environmental stimulus, including bacteria in the gastrointestinal tract [15]. To evaluate and monitor clinical disease activity in AS, the Bath Ankylosing Spondylitis Disease Activity Index (BASDAI) has been used. This index is obtained by summing the values of a visual analog scale (VAS) that evaluates six items, namely: fatigue, axial pain, peripheral pain, enthesitis, duration, and intensity of morning stiffness. BASDAI values are internationally used (BASDAI $\geq 4$ is deemed as high disease activity) [16]. Bath Ankylosing Spondylitis Functional Index (BASFI) is a set of 10 questions designed to decide the degree of functional limitation in AS patients. It is measured using a visual analogue scale (ranging from 0 being easy and 10 being impossible) and the questions are focused on the person's ability to perform specific functional tasks. The first 8 questions consider activities related to functional anatomy. The final two questions assess the patients' ability to cope with everyday life. It is included in the ASAS core sets for Ankylosing Spondylitis assessment. The mean of the ten questions gives the Bath Ankylosing Spondylitis Functional Index (BASFI) score, which is a set of 10 questions designed to decide the degree of functional limitations in AS patients [17]. The higher the BASFAI score, the more the patient is functionally limited. The Ankylosing Spondylitis Disease Activity Score (ASDAS) is a measure of axial spondyloarthritis (axSpA) disease activity with validated cut-offs endorsed by the Assessment of SpondyloArthritis international Society (ASAS) and OMERACT (Outcome Measures in Rheumatoid Arthritis Clinical Trials). The 2017 update of treat-to-target recommendations in axial and peripheral SpA state that the preferred mea- sure to define the target in axSpA is the ASDAS. ASDAS cut-offs for disease activity states are 1.3 separating the inactive disease from moderate disease activity, at least 2.1, high disease activity, and more than 3.5 very high disease activity [18]. The cornerstone of the non-pharmacological treatment of patients with AS is patient education and regular exercise. Patient education is advised as an integral part of recommendations for the management of early arthritis and AS [19]. The primary goal of patient education is no longer only knowledge transfer and disease control, but also to help patients to manage their illness, adapt to their disease, and maintain quality of life. Knowledge is a palliative force against the damaging effects of chronic illness and a description of the tendency of patients to reconstruct stories to bridge a gap between medical explanations and their own understanding of etiology [20]. Knowledge acquisition is a complex procedure and depends on patient intelligence, level of education, motivation teaching style, and content. Different models have been identified to increase the level of knowledge, with educational courses and information booklets among the most common [21, 22]. Acquisition of specific disease knowledge and education programs can benefit patients with chronic conditions mainly through improvements in self-efficacy, which is defined as the expectation an individual has in their ability to achieve a beneficial change and allows patients to participate in their own care [23], improvement of compliance, changing behavior and, to a lesser extent increase or improve the level of knowledge. And by proper knowledge, we can build trusting therapeutic relationships between patients and the rheumatology team. Patients may have a certain amount of knowledge and concept or their understanding about their disease, but this may be flawed or overestimated and can never fully or get balance with the expertise of the medical consultation. Overestimating their knowledge about their illness could have two effects on patients: it may decrease their motivation to learn more about their condition because by their assessment they already know enough about their illness and have the best knowledge to manage it, and it may lead them to make choices about their health independently [24]. Patients may have multiple views, by careful collection, these views are tried to be more directed and specific, and by a discussion of the consequences of chronic illness on patients and the possible role of the level of knowledge, by all of these, patient's understanding of chronic AS 
illness and its experience will be deepened. The explanation of the process of spinal fusion or ankylosis to patients with AS will help to explain the associated pain, stiffness and restricted movement, and help patients to fellow exercise programs and adhere to medication regimes in order to prevent ankylosis occurring. The same thing goes about extra skeletal symptoms, such as potential eye involvement. The importance of evaluating patients' knowledge about their specific disease have recognized by several investigators and educators. This is the reason for multiple studies that developed tools to evaluate the knowledge of chronic diseases, such as rheumatoid arthritis [25, 26], fibromyalgia [27], low back pain [28, 29], and AS [30, 31]. With physical therapy, an education with effective corrected knowledge has been recommended as non- pharmacological treatment of the disease, according to EULAR (European League Against Rheumatism) recommendation, 2016 [32].

\section{Patients AND methods}

This is a cross-sectional study. Patients with an established diagnosis of ankylosing spondylitis, depending on fulfilling modified New York criteria 1984, who have access to the Rheumatology Unit at Baghdad Teaching Hospital, are included in the study.

A consecutive sample of 200 Iraqi patients with established AS diagnosis were recruited, with disease onset after the age of 16 years, and disease diagnosis duration at least 6 months. AS Data were collected between November 2017 and September 2018. The study protocol was approved after review, and official permission was obtained from the Iraqi Board for Medical Specializations. Written consent was obtained from 197 participants, and fingerprint was obtained from the illiterate 3 participants, by a pre administered letter emphasizing the anonymous and confidential nature of the questionnaire. Privacy was assured during the personal interview, and all identifying information was concealed during statistical analyses.

Socio-demographic data were taking (age, name, gender, BMI (the equation $\mathrm{BMI}=$ weight $\mathrm{kg} /$ height $\mathrm{m}^{2}$ ), residence, marital status, smoking (smoker, X-smoker and non-smoker), with different educational level (illiterate, read \& write, primary school, secondary school, and university level), occupation and disease duration (6 months at least). Patients were on different medications (NSAIDs, bDMARDs as monotherapy, or combination with sDMARDs). Disease activity measurement was done by BASDAI [16]; functional disability by BASFI [17], for all patients and its association with the level of knowledge was included. Patients had interviewed and answered a questionnaire, which was including 4 knowledge Areas:

Area A. General Knowledge about AS, comprising etiology, symptoms musculoskeletal and extra musculoskeletal, and laboratory blood tests.

Area B. Immuno-genetics test (HLA-B27 antigen) and inheritance.

Area C. General Management, including pharmacological treatment and its side effects, physical therapy and exercise (exercise type \& proper duration and its role in treatment).

Area D. Joints protection, pacing, and priorities.

The questionnaire contained 18 questions, in total, with multiple possible responses or answers, one or two would be correct responses in each question. One point for each correct answer, then the points of all areas was summed to give a final score. The total correct score was 29 from 92 total possible responses. A 'don't know' response was added to enhance compliance of reluctant patients.

In Area A, total questions were 4 , with the total correct score of 8. In Area B, total questions were 2, with total correct score 2. In Area C, total questions were 9, with a total correct score of 15. In Area D, total questions were 3 , with total correct score 4, as shown in table 2.

All areas questions were answered during interviews at the rheumatology unit in Baghdad teaching hospital. Patients made free choices after reading, translating, and explanation of each question by a doctor. All 200 AS patients were keened to participate, and no patient had help from the family or the Health providers. Patients had received their knowledge or information about their disease AS, from different sources such as websites, rheumatologists, and even from discussion with each other.

The clinical and demographic data were analyzed using descriptive statistics of the participants' data, and knowledge scores were computed, a mean and standard deviation for numerical variables, and frequency and percentage for categorical variables were calculated. Student's t-test and Pearson's correlation coefficient for numerical data and univariate correlation by the Spearman correlation coefficient were used, in order to correlate the results from the questionnaire of knowledge with the clinical and demographic parameters of the participants. Pearson's chi-squared test $\left(x^{2}\right)$ is used to determine whether there is a significant difference between the expected frequencies and the observed frequencies in one 
or more categorical data. The statistical significance level was set at $p<0.05$. The standard error of a correlation coefficient is used to determine the confidence intervals around a true correlation of zero. It has a value between $(+1)$ and $(-1)$, where (1) is total positive linear correlation, $(0)$ is no linear correlation, and $(-1)$ is total negative linear correlation. The interaction which describes noncausal associations were considered in the context of regression analyses or factorial experiments, and by simple setting in which interactions were analyzed using Analysis of variance (ANOVA). The results were disclosed by using Microsoft Office 2010 for windows. The data analyzed using Statistical Package for Social Sciences (SPSS) version 25.

\section{Results}

All patients knew that their diagnosis was AS (no other diagnoses). Eighteen females and 182 males participated. Body mass index (BMI) mean was $28.95 \pm 4.04 \mathrm{~kg} / \mathrm{M}^{2}$ (range 18-43). Their mean age was $36.89 \pm 9.65$ (range 18-74), and the mean disease diagnosis duration was $8.45 \pm 7.54$ years, (range 6 months - 40 years). Patients had different educational levels (3 illiterate, 2 read and write, 60 primary school, 74 secondary school and 61 university level), and different occupations (housewife, wage earner, policeman, military solder, driver, employee, teacher, engineer, and retired ). One hundred fourteen were smokers, 15 were X-smokers, and 71 non-smokers, all socio-demographic data are shown in table 1. Their treatments were: $168(84 \%)$ of patients on biologics mono-therapy. 23 (11.5\%) on combination of sDMARD + bDMARD, and 9 $(4.5 \%)$ on NSAID only. The mean total score of the questionnaire was $16.28 \pm 2.49$ (range 2-26). Total possible responses or answers were 92, total correct responses were 29 , and every correct response takes one point. There was no significant statistical association between the mean total score and the gender $(p=0.14)$, as shown in fig. 1 ; age $(p=0.93)$, marital status ( $p=0.73$ ), as shown in fig. 2 ; smoking $(p=0.65)$, as shown in fig. 3 ; residence $(p=0.56)$, BMI $(p=0.23)$, BASDAI $(p=0.42)$, and BASFI $(p=$ 0.81 ), table 1 . While between the mean total score and the level of education, occupation, and engineer job, there was a highly significant statistical relationship, p-values respectively were $0.0004,0.002$, and 0.04 , as shown in fig. 4 , fig. 5 , resp. There were no statistical correlations between the mean total score of the questionnaire and BASDAI, BASFI, age, and disease diagnosis duration.
Area A: General knowledge, etiology, symptoms, and laboratory blood tests. The mean total score is $3.63 \pm 1.61$. The maximum possible score is 8 . The maximum achieved score is 7 , as shown in table 2 and fig. 6.

In area $A, 65(32.5 \%)$ have been recognized that the cause of their disease is unknown or autoimmune. $74(37 \%)$ have thought of back injuries of heavy exercise, which may cause AS. 49 (24.5\%) don't have any idea about the cause. 12 (6\%) of patients thought that AS is an infectious disease. 49 (24.5\%) know that AS can involve more than one member in the same family. 151 (75.5\%) don't know that AS can be presented in more than one member of the same family. All patients recognized that the main feature is back pain, $153(76.5 \%)$ don't know the first presentation could not be in the back. 160 (80\%), recognized that AS is a chronic disease. $14(7 \%)$, thought that AS is a curable disease, while 26 (13\%) don't know the attitude of AS. 127 ( 63.5\%) get worse in cold weather. About eye and lung involvement in AS, 79 (39.5\%) get the correct answer. Only $3(1.5 \%)$ made a correct choice of CRP and ESR as a routine blood test used to assess disease activity.

Area B: HLA-B27 antigen and inheritance. The maximum possible score is 2. Mean achieved score is $0.26 \pm 0.51(0-2)$, the maximum total score is achieved by just $6(3 \%)$, as shown in table 2 and fig. 6.

Only $43(21.5 \%)$, recognized that HLA-B27 is a useful blood test to assess the tendency to develop AS. The inheritance of AS is a cause of confusion with the majority of participants, 194 patients (97\%) don't know.

Area C: Drug treatment and physical therapy. The maximum possible score is 15 , the mean achieved score $(9.53 \pm 2.42),(0-14)$, as shown in table 2 and fig. 6.

Area C shows, 131 (65.5\%) of patients considered medications as a pain killer \& anti-inflammatory, and $69(34.5 \%)$ thought, they are just a pain killer. bDMARDs, side effects make a difficult question to the patients; just 48 (24\%) recognized that reactivation of latent TB, HBV, and HCV could be one of the Side effects, and 8 (4\%) of 200 patients know that bDMARDs can rarely cause malignancy. About eye involvement medications, only 14 (7\%) know that doctors can use NSAID, sDMARDs, bDMARDs as a treatment of eye involvement in AS. About exercise role in AS management, the majority of patients 186 (93\%), know that exercise is an important part of management, and regular daily exercise is a wise approach to keep 
active. The majority of patients identified the role of good posture and knew that fluctuations of disease with spells of remission and flares might occur. No patient considered exercises as a cure or a potential for damage, and all patients are aware that even with regular exercise, normality will not be restored. A percent of correct responses about the most suitable activities for people with AS is found in approximately half no. Q11. In fact, swimming and muscle-strengthening exercises are chosen by 103 (51.5\%). Nobody considered acupuncture as a cure, the question concerning the beneficial effect of exercise in water is answered by the majority of patients, 190 (95\%), and $122(61 \%)$ don't know the proper duration of the exercise. Regarding Kyphosis reverse exercise, which is lying down on the face for 15-30 min. few times in a day can reverse or prevent kyphosis, the correct answer is recognized by only 63 (31.5\%).

Area D: Joint protection, pacing, and priorities. The maximum possible score is 4 , minimum to maximum are (0-4), mean score $(2.87 \pm$ 1.06), the full score is achieved by 67 (33.5\%), as shown in table 2 and fig. 6.

Rest in AS Question 8 (two responses) is correctly identified by 128 (64\%), they answered correctly that, a spell off work or in the hospital may be necessary when the disease is very active rather than rest in bed for most of the day, $147(73.5 \%)$ of patients identified that lying on the front for sometime before going to bed and before rising in the morning, is a good attitude for back stiffness. Regarding an ideal bed for patients with AS, the correct answer (firm) is identified by 107 (53.5\%). Carry out range of movement exercises within pain- free limits, as the one activity which should be carried out when all joints are painful and stiff, as in acute flare, this question is recognized correctly by the majority of patients 191 $(95.5 \%)$.

\section{INFORMATION SOURCES OF THE 200 AS PATIENTS}

There were multiple sources of information that AS Iraqi patients based on their responses, $50 \%$ got their information from a rheumatologist, $5 \%$ depended on multiple websites, $2 \%$ of patients depended on discussion with each other, $5 \%$ got information from a rheumatologist, websites, and discussion. From rheumatologists and websites, information sources frequency was $32 \%$, rheumatologists and discussion with each other was $6 \%$, as shown in fig. 7 .

Table 1. Frequency distribution of the 200 AS Iraqi patients by socio-demographic variables

\begin{tabular}{|c|c|c|c|c|}
\hline Variables & Total no. $=\mathbf{2 0 0}$ & $\%$ & Mean \pm SD & P-Values \\
\hline Age & & & $36.89 \pm 9.65$ & \multirow{2}{*}{$0.93^{*}$} \\
\hline $18-40 />40 y$ & $139 / 61$ & $69.50 \% / 30.5 \%$ & & \\
\hline \multicolumn{3}{|l|}{ Gender } & & \multirow{2}{*}{$0.14^{*}$} \\
\hline Male/Female & $182 / 18$ & $91 \% / 9 \%$ & & \\
\hline \multicolumn{3}{|l|}{ Marital status } & & \multirow{2}{*}{$0.73^{\star *}$} \\
\hline Married/unmarried/divorce & $158 / 41 / 1$ & $79 \% / 20.5 \% / 0.5 \%$ & & \\
\hline \multicolumn{3}{|l|}{ Residency } & & \multirow{2}{*}{$0.56^{*}$} \\
\hline Baghdad/other governorates & $134 / 66$ & $67 \% / 33 \%$ & & \\
\hline \multicolumn{3}{|l|}{ Occupation } & & \multirow{7}{*}{$0.002^{\star \star}$} \\
\hline housewife & 15 & $7.5 \%$ & & \\
\hline wage earner & 80 & $40 \%$ & & \\
\hline Policeman/military soldier & $5 / 11$ & $2.5 \% / 5.5 \%$ & & \\
\hline Driver/Baker & $25 / 1$ & $12.5 \% / 0.5 \%$ & & \\
\hline Employee/student & $21 / 14$ & $10.5 \% / 7 \%$ & & \\
\hline Teacher/retired & $21 / 3$ & $10.5 \% / 1.5 \%$ & & \\
\hline engineer & 4 & $2 \%$ & & $0.04^{*}$ \\
\hline \multicolumn{3}{|l|}{ Smoking } & & \multirow{2}{*}{$0.65^{\star \star}$} \\
\hline Smoker, X-smoker, non-smoker & $114,15,71$ & $57 \%, 7.5 \%, 35.5 \%$ & & \\
\hline \multicolumn{3}{|l|}{ Educational level } & & \multirow{4}{*}{$0.0004^{* *}$} \\
\hline Illiterate/read and write & $3 / 2$ & $1.5 \% / 1 \%$ & & \\
\hline Primary/Secondary school & $60 / 74$ & $30 \% / 37 \%$ & & \\
\hline University level & 61 & $30.50 \%$ & & \\
\hline Disease Diagnosis duration 6 months $/ 6 \mathrm{~m}-40 \mathrm{y}$ & $2 / 198$ & $1 \% / 99 \%$ & $8.45 \pm 7.54$ & $0.32^{*}$ \\
\hline BASDAI/BASFI & & & $2.9 \pm 1.3 / 2.8 \pm 1.7$ & $0.42 / 0.81^{* *}$ \\
\hline
\end{tabular}

No = number, SD = standard deviation, $\mathrm{P}$ value = probability value, BASDAI = Bath Ankylosing Spondylitis Disease Activity Index, BASFI

$=$ Bath Ankylosing Spondylitis Disease Functional Index, $\mathrm{sec}=$ secondary. ( $\mathrm{P}$ value $<0.05$ is considered significant).

* Student's t test; **Analysis of variance (ANOVA) 
Table 2. The mean score of the questionnaire's areas. Mean $\pm S D$ in 200 AS sample of Iraqi patients

\begin{tabular}{|l|c|c|c|c|}
\hline $\begin{array}{l}\text { Knowledge } \\
\text { Areas }\end{array}$ & Mean \pm SD & Minimum score & Maximum possible score & Maximum achieved score \\
\hline A (general knowledge) & $3.63 \pm 1.61$ & 0 & 8 & 7 \\
\hline B (HLA-B27 and inheritance) & $0.26 \pm 0.51$ & 0 & 2 & 14 \\
\hline C (treatment options) & $9.53 \pm 2.42$ & 0 & 4 & 4 \\
\hline D (joints protection) & $2.87 \pm 1.06$ & 0 & 4 & 14 \\
\hline
\end{tabular}

Table 3. Comparison between the current study and the other three studies conducted in the UK, France, and Brazil by usingsimilar questionnaire

\begin{tabular}{|c|c|c|c|c|}
\hline Variables & Current study & UK study & French study & Brazilian study \\
\hline The mean total score & $16.28 \pm 2.49$ & $19.45 \pm 3.23$ & $16.4 \pm 4.8$ & $17.33 \pm 3.4$ \\
\hline Area A & $3.63 \pm 1.61$ & $7.23 \pm 0.23$ & $\begin{array}{c}49 \pm 31 \text { mean } \% \text { of correct } \\
\text { answers }\end{array}$ & $5.17 \pm 1.70$ \\
\hline Area B & $0.26 \pm 0.51$ & $2.63 \pm 0.52$ & $\begin{array}{c}48 \pm 33 \text { mean } \% \text { of correct } \\
\text { answers }\end{array}$ & $0.97 \pm 0.85$ \\
\hline Area C & $9.53 \pm 2.42$ & $8.81 \pm 0.54$ & $\begin{array}{c}64 \pm 29 \text { mean } \% \text { of correct } \\
\text { answers }\end{array}$ & $7.2 \pm 1.05$ \\
\hline Area D & $2.87 \pm 1.06$ & $4.74 \pm 0.57$ & $\begin{array}{c}41 \pm 26 \text { mean } \% \text { of correct } \\
\text { answers }\end{array}$ & $3.43 \pm 1.04$ \\
\hline Gender & $p=0.14^{*}$ & $p=0.19$ & Female $p=0.03$ & $p=0.71$ \\
\hline Age & $p=0.93^{*}$ & $p=0.4$ & $p>0.05$ & $48.4 \pm$ SD 9.5 \\
\hline Educational level & $p=0.0004^{* *}$ & $p=0.57$ & $p=0.018$ & $p=0.001$ \\
\hline Occupation & $p=0.002^{* *} /$ Engineer $0.04^{*}$ & Not included & Not included & $p=0.19$ \\
\hline Residence & $p=0.56^{*}$ & Not included & Not included & Not included \\
\hline BASDAI & $p=0.8^{* *} / \operatorname{cor}-0.04^{* * *}$ & Not included & Not included & No significant relationship \\
\hline BASFI & $p=0.52^{* *} / \operatorname{cor}-0.13^{* * *}$ & Not included & Not included & No significant relationship \\
\hline Information sources & $\begin{array}{l}\text { Rheumatologist, websites, and } \\
\text { discussion }\end{array}$ & ARC booklets & No formal sources & No formal sources \\
\hline Sample number & 200 & 62 & 90 & 60 \\
\hline Disease duration & $p=0.62^{*}$ & $p=0.78$ & $p>0.05$ & $p=0.30$ \\
\hline Ethnicity & Not included & Not included & Not included & $p=0.02$ \\
\hline
\end{tabular}

$\mathrm{D}=$ standard deviation, $\mathrm{p}=$ probability value, BASDAI = Bath Ankylosing Spondylitis Disease Activity Index, BASFI = Bath Ankylosing Spondylitis Functional Index, ARC = Arthritis and Rheumatism Council booklet

*Student's t-test; **Analysis of variance (ANOVA); ${ }^{* * *}$ Spearman's correlation coefficient

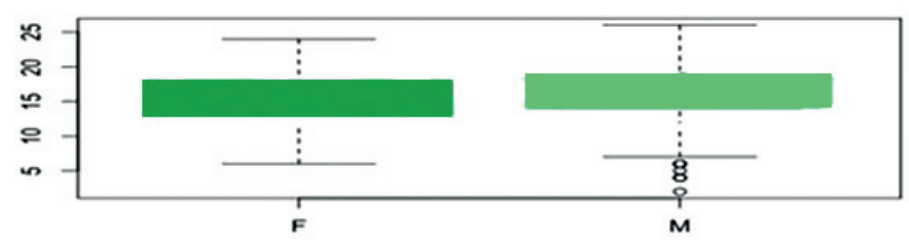

Fig. 1. The relationship between the mean total score of the questionnaire and gender in 200 AS Iraqi patients

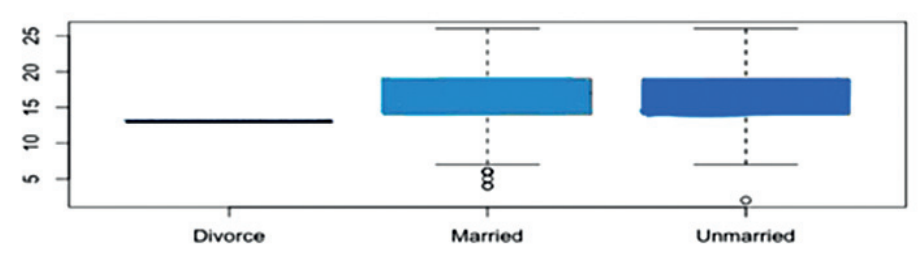

Fig. 2. The relationships between the mean total score of the questionnaire and marital status in 200 AS Iraqi patients 


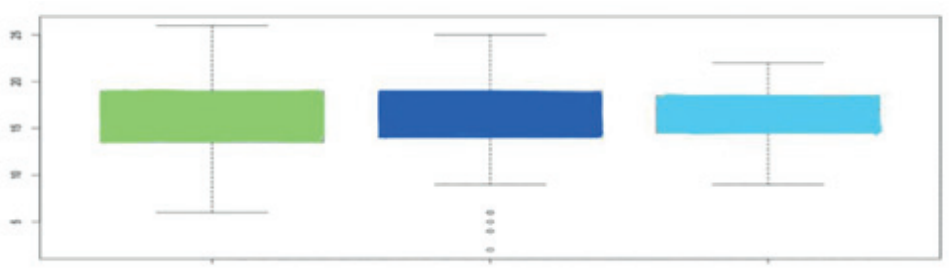

Non smokers

Smokers

X-smokers
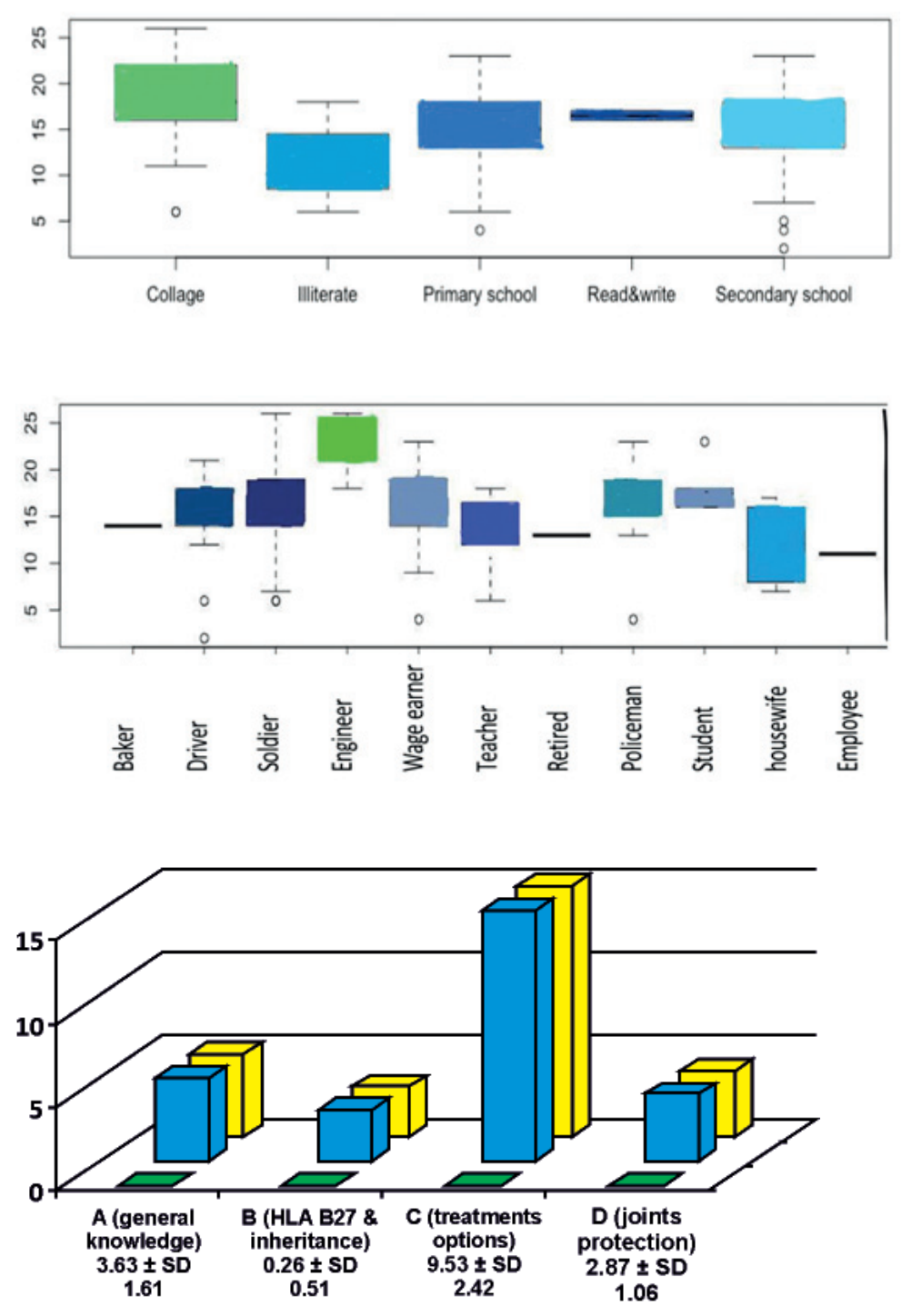

$\square$ Minimum score $\square$ Maximumu achiened score $\square$ Maximumu possible score
Fig. 3. The relationship between the mean total score of the questionnaire and smoking in 200 AS Iraqi patients

Fig. 4. The relationship between the mean total score of the questionnaire and educational level in 200 AS Iraqi patients

Fig. 5. The relationship between the mean total score of the questionnaire and occupation Engineer job in 200 AS Iraqi patients
Information sources' frequencies

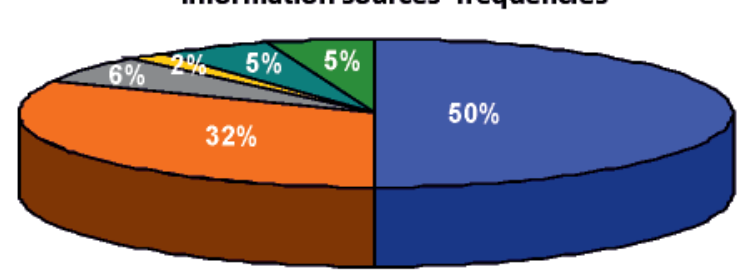

$\square$ Rheumatologist

$\square$ Rheumatologist and websites

$\square$ Rheumatology and discussion

with each other

$\square$ Discussion with each other

$\square$ Websites

Rheumatology, websites and discussion
Fig. 7. Information sources with frequencies of the 200 AS Iraqi patients, who undergo a self-administered questionnaire 


\section{Discussion}

This study used a questionnaire with a physician interview to assess the level of knowledge in a sample of AS Iraqi patients. This questionnaire was based on a previously validated one for AS [30] and showed a high index of readability, reliability, and consistency so that it could allow a provision of reliable information. This study showed that Iraqi AS patients had a low level of knowledge, or they displayed limited knowledge of AS, with different wrong beliefs on specific aspects of their disease. Many conclusions can be drawn from these results, strongly suggests poor quality of patients' information sources, due to lack of regular, informative, proper, logic, and simplified educational program. Iraqi AS patients depend on multiple sources of information about their disease, including rheumatologists, different websites, and even discussion with each other. The current study revealed a significant statistical relationship between the mean total score of the questionnaire and the educational level and occupation; for example, engineers show a high level of knowledge and seem to be more interested in their disease. They might have easy access to a specific and accurate source of information. The study didn't show any statistical relationship or correlation between the mean total score of the used questionnaire and BASDAI [16], BASFI [17]. The mean score of Area $A$, which included general knowledge about AS, etiology, skeletal and extraskeletal symptoms, and laboratory blood tests, was $3.63 \pm 1.61$ (the maximum possible score was 8 ). The main explanation of this low level of knowledge is poor or lack of informative, simplified educational programs and the weak communication between patients and rheumatologists. In Area B, the majority of AS patients did not recognize the importance of HLA-B27 as a marker of disease susceptibility. The mean score was $0.26 \pm 0.51$ (the maximum possible score was 2). HLA-B27 test will not answer whether the patient's children will develop the disease or not; however, the relationship between this marker and AS inheritance is still not well known. So area B made a confusing state and was a very difficult, unexpected part for the majority of patients. This result is due to a lack discussion with rheumatologists about AS causes and associations. In Area C, which included drug treatment and physical therapy, the mean score was 9.53 \pm 2.42 (the maximum possible score was 15). Patients had a moderate level of knowledge about treatment in AS, including anti-inflammatory and pain killer medications. But, they barely knew about the side effects of their drugs, which currently use, and they disclosed a very low level of knowledge about used medications in cases with eye involvement. Patients had a high level of knowledge in the area of physical treatment, reflected by their responses on posture and exercise. The majority of patients knew that exercise is an important part of treatment for AS, and regular daily exercise is a wise approach to keep them active. They had acceptable information about sport types, proper duration of sports, and kyphosis reverse exercise. The explanation is that most patients had received physical therapy at some time during their disease, and exercises undoubtedly relieve pain and stiffness in AS so that the proper concept will be well received with exercise. Moreover, exercises may give rapid, objective results in a pleasant atmosphere (e.g., pool, group exercises), thus increasing the readiness of patients to learn more and more about AS. In Area D, about half of the AS patients sample identified the role of good posture and the advantage of a firm bed. The majority knew that fluctuations of disease with spells of remission and flares might occur. No patient considered exercises as a cure for damage, and most of the patients knew that even with regular exercise, normality would not be restored. In a UK study which was published in 1998 [29], the level of knowledge was higher than the level in the present study, the mean total score of questionnaire was high (19.45 \pm 3.23, range 6-24). Patients in the UK showed a good level of knowledge in areas A, C, and D; and a moderate level of knowledge in area $B$, which made some difficulty to the participants. There was no significant statistical relationship between the mean total score and age, gender, disease duration, or level of education. AS patients had a high level of knowledge with minimal wrong beliefs on specific aspects of the disease. The good level of observed knowledge may be attributed to the fact, that UK patients had read the Arthritis and Rheumatism Council booklet ARC booklet on AS at least once and due to the good quality of the ARC booklet, which was apparently written in a logical and simple way, allowing easy comprehension of the subject. Furthermore, many patients had also attended physiotherapy and special education courses held by NASS (the British National AS Society), run by physiotherapists, so undoubtedly gaining useful advice. In 2004, another study was published in France [32], which was done at six rheumatology departments in tertiary care hospitals throughout France for assessment of AS knowledge and to identify factors associated with this knowledge. 90 AS patients were receiving follow 
up in France, completed a disease knowledge self-administered questionnaire and showed a Correct Answer Score CAS, and a Correct Item Score $\mathrm{CIS}$. Correlations between these scores and other factors were assessed. Mean CAS was $16.4 \pm 4.8$, and mean CIS was $7.3 \pm 3.1$, which indicated a low level of knowledge like the resulted score in the current study. Female gender and higher educational level showed a better level of knowledge compared to male and those with lower educational level, and that might be due to female, and those with higher education levels read about $A S$, being aware of $A S$ support groups, and had received longer tertiary care at hospital management. In the France multivariate analysis study, only three factors were associated independently with the level of knowledge: reading about $A S$, level of general education, and awareness of an AS support group. Level of knowledge in AS French patients was also low because none of French AS patients had followed classes on AS, and only a small sample had read about their disease; furthermore, the AS informative booklets that are now widely distributed in France, were not available before 2004. A study in Brazil was published in 2016 [33], it assessed the level of knowledge in 60 AS Brazilian patients, in two groups (adaptation and reliability). Most of the patients who were evaluated had not completed a high school education. The study found a strong correlation between educational level and the level of knowledge. In the cultural adaptation phase, there was a statistically significant difference between ethnic groups regarding knowledge; white participants disclosed a higher level of AS knowledge compared with black or brown ones. Brazilian observed that low level of knowledge about AS was correlated with ethnicity, (which was not included in the current study) and with educational levels (similar to the result in the current study), which reflected the racial and educational situation in Brazil. In Area A, the mean achieved score was $5.17 \pm 1.70$, which was more than area $A$ in the present study. The level of knowledge was low, mainly in area $B$, and had a mean of $0.97 \pm 0.85$ and seem to be similar to area $B$ in the present study. The question about HLA-B27 and its association with AS inheritance in area $B$ gave rise to the greatest amount of confusion among the Brazil sample AS patients. While other areas showed average percentages of correct answers of greater than $60 \%$. In Area C, the majority of Brazil AS patients correctly answered the questions about the most appropriate type of physical activity for AS, also obtained $100 \%$ correct answers to the question about the impor- tance of exercise. The reasons might be most of the patients included in the Brazilian study had already undergone physiotherapy or had participated in other previous studies on physical activity related to AS. Area D showed a mean score of $3.43 \pm 1.04$. A conclusion that might be getting from this area is that patients with greater impairment had higher levels of knowledge. The translated questionnaire copy that used in the assessment of Brazil AS patients' knowledge made clear the individual need of education about AS disease, facilitating the evaluation and guidance of what should be done to each patient optimizing the conduct regarding education and knowledge improvement.

In conclusion, the present study disclosed that AS Iraqi patients have a low level of knowledge, high ignorance, unawareness, and wrong thoughts about specific aspects of their disease, which may reinforce the recommendation of this study. It's recommended to spend more time listening to the AS patients' thoughts; make sure you response carefully to their questions. Advice to improve the low, wrong patients' concepts, by easily readable booklets, leaflets, videos or, group rather than individualized educational health sessions, by using simplified, informative materials. They are helping patients to organize the treatment options and to acquire the abilities necessary for self-management of the consequences of AS. Although education should be offered to all AS patients, the need may be focused on those with impaired school or low educational level.

\section{Acknowledgment}

We would like to thank Prof. Sami Salman, Ass. Prof. Faiq I Gorial; Ass. Prof. Sabeeh Mashhadani for their insightful comments, motivations, and encouragement.

Conflict of interest: No.

\section{References}

1. Hamilton L, Barkham N, Bhalla A, et al. BSR and BHPR guideline for the treatment of axial spondyloarthritis (including ankylosing spondylitis) with biologics. J Rheumatol 2016;56(2):313-316.

2. Rudwaleit M, Khan MA, Sieper J. The challenge of diagnosis and classification in early ankylosing spondylitis: do we need new criteria? Arthritis Rheum 2005;52(4):1000-1008.

3. Van der Linden SM, Valkenburg HA, de Jongh BM, et al. The risk of developing ankylosing spondylitis in HLA-B27 positive individuals: a comparison of relatives of spondylitis patients with the general population. Arthritis Rheum 1984;27:241249.

4. Li Z, Brown MA. Progress of genome-wide association studies of ankylosing spondylitis.CTI 2017,6(12) 
5. Nasution AR, Marjuadi A, Kunmartini S, et al. HLA-B27 subtypes positively and negatively associated with spondylarthropathy. J Rheumatol 1997;24:1111-1114.

6. López-Larrea C, Sujirachato K, Gonzalez-Roces S, et al. HLA-B27 subtypes in Asian patients with ankylosing spondylitis. Evidence for new associations. Tissue Antigens 1995;45(3):169-176.

7. Khan MA. Update on spondyloarthropathies. Ann Intern Med 2002;136(12):896-907.

8. Jaakkola E, Herzberg I, Laiho K, et al. Finnish HLA studies confirm the increased risk conferred by HLA B27 homozygosity in ankylosing spondylitis. Ann Rheum Dis 2006;5(6):775-780.

9. Al-Bedri KZ. Prevalence, Clinical Features, and Radiological Features of Iraqi Patients with Ankylosing Spondylitis. JNSR 2014;4(24).

10. Al-Rawi ZS, Al-Shakarchi HA, Hasan F, et al. Ankylosing spondylitis and its association with the histocompatibility antigen HL-A B27: an epidemiological and clinical study. J Rheumatol 1978;17(2):72-75.

11. Ramos M, Paradela A, Vazquez $M$ et al. Differential association of HLA-B*2705 and $B^{*} 2709$ to ankylosing spondylitis correlates with limited peptide subsets but not with altered cell surface stability. J Biol Chem 2002;277(32):28749-28756.

12. Van Gaalen FA. Does HLA-B*2706 protect against ankylosing spondylitis? A meta-analysis. Int J Rheum Dis 2012;15(1):8-12.

13. François RJ, Neure L, Sieper J, et al. Immunohistological examination of open sacroiliac biopsies of patients with ankylosing spondylitis: detection of tumour necrosis factor a in two patients with early disease and transforming growth factor $\beta$ in three more advanced cases. Ann Rheum Dis 2006;65(6):713-720.

14. Layh-Schmitt G, Colbert RA. The IL-23/LL-17 Axis in Spondyloarthritis. Curr Opin Rheumatol 2008;20(4):392-397.

15. Ebringer A. The relationship between Klebsiella infection and ankylosing spondylitis. Bailliere Clin Rheumatol 1989;3(2):321-338.

16. Sieper J, Rudwaleit M, Baraliakos X, et al. The Assessment of SpondyloArthritis international Society (ASAS) handbook: a guide to assess spondyloarthritis. Ann Rheum Dis 2009,68(Suppl 2):1-44.

17. Calin A, Garrett S, Whitelock H, et al. A new approach to defining functional ability in ankylosing spondylitis: the development of the Bath Ankylosing Spondylitis Functional Index. J Rheumatol 1994;21(12):2281-2285.

18. Machado PM, Landewé R, van der Heijde D. Assessment of SpondyloArthritis international Society (ASAS) Ankylosing Spondylitis Disease Activity Score (ASDAS): 2018 update of the nomenclature for disease activity states. Ann Rheum Dis 2018;77:1539-1540

19. Van der Heijde D, Sieper J, Maksymowych WP, et al. Assessment of SpondyloArthritis international Society. 2010 Update of the international ASAS recommendations for the use of anti-TNF agents in patients with axial spondyloarthritis. Ann Rheum Dis 2011;70(6):905-908.

20. Thompson B. Education and learning for people with Ankylosing Spondylitis. MD theisis, Newcastle University, 2011. 59.
21. Maggs FM, Jubb RW, Kemm JR. Single-blind randomized controlled trial of an educational booklet for patients with chronic arthritis. Br J Rheumatol 1996;35(8):775-777.

22. Mahmud T, Comer M, Roberts $\mathrm{K}$ et al. Clinical implication of patients' knowledge. CJR 1995;14:627-630.

23. Helliwell PS, O'Hara M, Holdsworth J, et al. A 12-month randomized controlled trial of patient education on radiographic changes and quality of life in early rheumathoid arthritis. Rheumatol 1999;38:303-308.

24. Salman S, SAlnuaimi A, Lateef NA, et al. Assessment of Knowledge and Attitude in a Sample of Patients with Rheumatoid Arthritis and Its Association with Disease Activity and Severity: A Cross-Sectional Study. OJRA 2014;4(04):226.

25. Kona Kaut I, Ezzhara abourazzak F, Jamila E, et al. Axial Spondyloarthritis and Cigarette Smoking. Open Rheumatol J 2017; 11:53-61.

26. Jennings F, Toffolo S, De Assis MR, et al. Brazil Patient Knowledge Questionnaire (PKQ) and evaluation of disease-specific knowledge in patients with rheumatoid arthritis. Clin Exp Rheumatol 2006;24(5):521-528

27. Suda AL, Jennings F, Bueno VC, et al. Development and validation of fibromyalgia knowledge questionnaire: Fkq. Rheumatol Int 2012;32(3):655-662.

28. Ribeiro LH, Jennings $F$, Jones $A$, et al. Effectiveness of a back school program in low back pain. Clin Exp Rheumatol 2008;26(1):81-88.

29. Tarimo N, Diener I. Knowledge, attitudes and beliefs on contributing factors among low back pain patients attending outpatient physiotherapy treatment in Malawi. S Afr J Physiother 2017;73(1):395.

30. Lubrano E, Helliwell P, Moreno P, et al. The assessment of knowledge in ankylosing spondylitis patients by a self-administered questionnaire. Rheumatology (Oxford) 1998;37(4):437-441.

31. Van der Heijde D, Dougados M, Davis J, et al. Assessment in Ankylosing Spondylitis International Working Group/Spondylitis Association of America recommendations for conducting clinical trials in ankylosing spondylitis. Arthritis Rheum 2005;52(2):386-394.

32. Van der Heijde D, Ramiro S, Landewé R, et al. 2016 update of the ASAS-EULAR management recommendations for axial spondyloarthritis. Ann Rheum Dis 2017;76(6):978-991.

33. Claudepierre P, Flipo RM, Sibilia J, et al. Patient knowledge of their disease: a French multicenter study in ankylosing spondylitis. Joint Bone Spine 2004;71(6):550-556.

34. Orlandi A, Brumini C, Jones A, et al. Translation to Brazilian Portuguese, cultural adaptation and reproducibility of the questionnaire" Ankylosing Spondylitis: What do you know?". Sao Paulo Med J 2016;134(5):407-416.

Submitted: 08.04.2020

$\triangle$ Correspondence address:

Saba Hussein Majeed

Rheumatology Department

Al-Kindy Teaching Hospital

Ministry of Health/Environment

Baghdad, Iraq

7733962400

Zip-code: 10001

Medicalresearch22@yahoo.com 